\title{
Noninvasive Assessment of Donor Area in Patients with Androgenetic Alopecia undergoing Hair Transplantation by Digital Imaging Technique
}

${ }^{1}$ Pavan Raj, ${ }^{2} \mathrm{C}$ Madura, ${ }^{3} \mathrm{BS}$ Chandrashekar

\begin{abstract}
Trichoscopic digital imaging is one of the safe, accurate and non invasive method of assessment of donor area for pre transplant evaluation that aids in further plan of action. Our study aimed to calculate the hair density, hair follicular unit density, grouping of hair, average hair per unit, total number hair follicles and follicular units in the safe donor zone. Thorough donor area assessment prior to the hair transplantation is very important to assess the yield of grafts and over all treatment outcome. It is useful in planning the utilization of the grafts for present and future surgeries depending on patient's age and progression of baldness
\end{abstract}

Keywords: Androgenetic alopecia, Digital imaging technique, Hair transplantation, Safe donor zone.

How to cite this article: Raj P, Madura C, Chandrashekar BS. Noninvasive Assessment of Donor Area in Patients with Androgenetic Alopecia undergoing Hair Transplantation by Digital Imaging Technique. Int J Dermoscop 2017;1(2):50-53.

Source of support: Nil

Conflict of interest: None

\section{INTRODUCTION}

Hair transplantation has become increasingly popular in recent years. In addition to medical therapy, more and more number of androgenetic alopecia (AGA) patients are seeking surgical management. There is a need for maximum harvest of grafts without affecting the cosmetic outcome of the donor area in severe grade of baldness. Therefore, thorough assessment of donor area with respect to the hair density, hair follicular unit density, hair grouping, and thickness of hair along with scalp laxity is necessary for a satisfying outcome.

${ }^{1,2}$ Consultant Dermatologist \& Dermatosurgeon, ${ }^{3}$ Chief Dermatologist

${ }^{1-3}$ Department of Dermatology, Academy of Cutaneous Sciences, Bengaluru, Karnataka, India

Corresponding Author: Madura C, CUTIS Academy of Cutaneous Sciences (CACS), 5/1, 4th main, MRCR Layout Vijayanagar, Bengaluru, Karnataka, India, e-mail: maduradr@ gmail.com
Trichoscopic digital imaging is one of the safest, accurate, and noninvasive methods of assessment of donor area for pretransplant evaluation that aids in further plan of action. ${ }^{1}$ There is dearth of literature on the assessment of various parameters in the donor area and hence, this study was taken up to assess the donor area in patients undergoing hair transplantation.

\section{AIMS AND OBJECTIVES}

The study aimed to calculate the following parameters in the safe donor zone: Hair density, hair follicular unit density, grouping of hair, average hair per unit, total number hair follicles and follicular units in the safe donor zone, and extent of miniaturization. We also assessed the variation of these parameters in relation to the grade of AGA and age of the patient.

\section{MATERIALS AND METHODS}

This was a prospective study conducted for a period of 1 year from January 2016 to December 2016. A total of 30 male patients with AGA seeking hair transplantation were enrolled in the study. Patients who had undergone hair transplantation earlier were excluded from the study.

The safe donor area in the occipital region was marked by identifying the occipital protuberance and the extent of miniaturized hair follicles (ascending and descending hairline). The safe donor area was measured by calculating the area formed by joining the markings. Three spots were marked in the safe donor area: one just above the occipital protuberance and the other two at a distance of $8 \mathrm{~cm}$ on either sides of the first point (Fig. 1). The hair length over these areas was trimmed to $1 \mathrm{~mm}$ and the digital imaging was done (FotoFinder).

The following parameters were noted in all the patients: Hair follicular units per $\mathrm{cm}^{2}$, hair density per $\mathrm{cm}^{2}$, hair grouping $(1,2,3,4$, and $>4)$, average hair per follicular unit, median thickness of hair, density of vellus, and terminal hair (Fig. 2). The observations were tabulated and the average values in all 30 patients were calculated. 

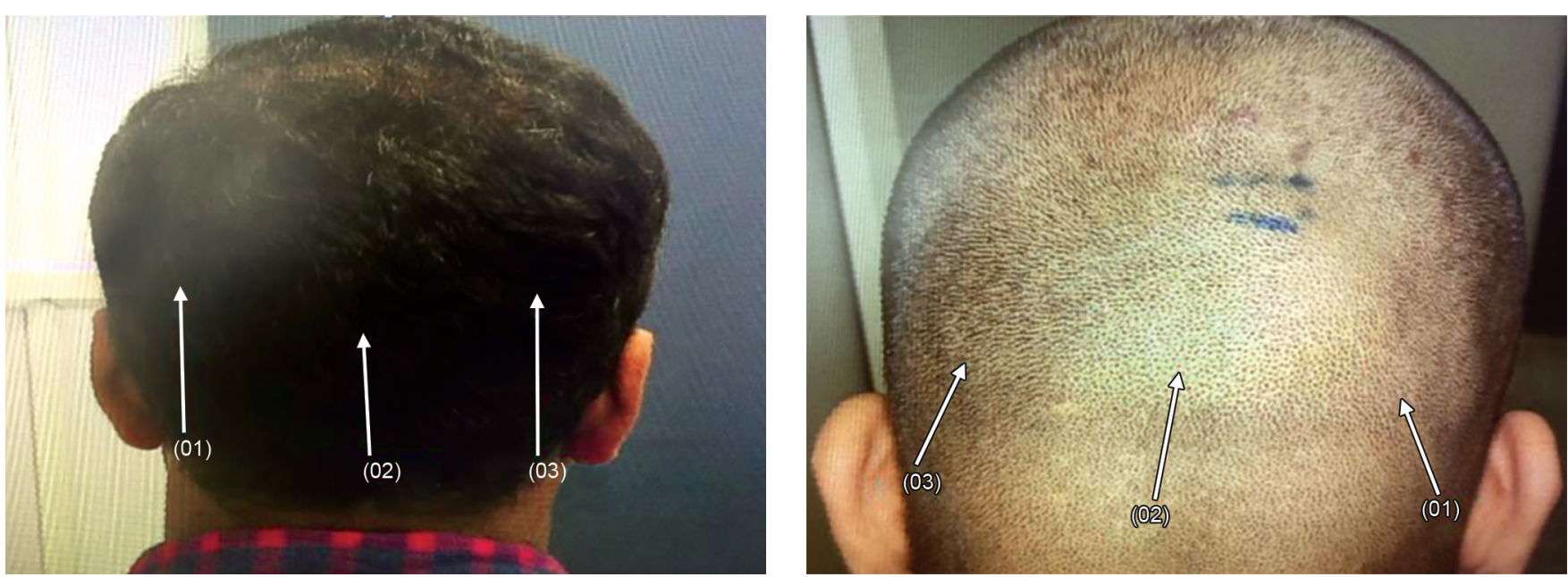

Fig. 1: Prominent markings on the safe donor region, for digital image analysis

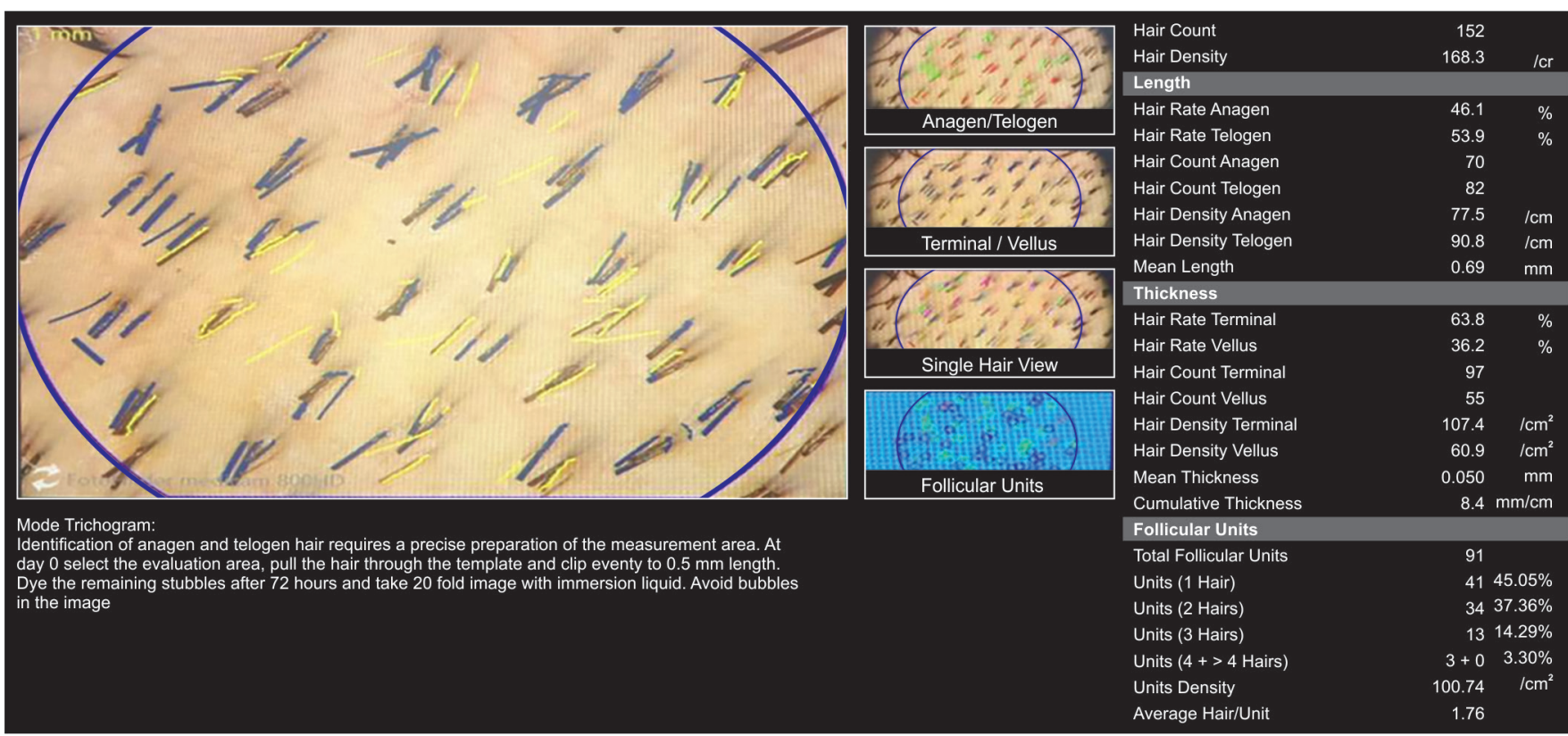

Fig. 2: Trichogram results with various parameters

\section{RESULTS}

The AGA ranged from grade III to grade VII according to the modified Norwood-Hamilton classification. Out of the 30 patients, 3 patients (10\%) had grade III baldness, 10 had grade IV $(33.33 \%), 9$ had grade V $(30 \%)$, 5 had grade VI (16.66\%), 3 had grade VII $(10 \%)$, and 6 patients $(20 \%)$ were of variant "a." The age of the patients from 22 to 44 years, and the mean age was 29.2 years. The average duration of AGA was 6.2 years. The average hair follicular units and density per $\mathrm{cm}^{2}$ was 112 and 220 respectively. Grouping of hairs showed maximum number of single hairs (42.26\%) followed by 2 hairs $(37.53 \%), 3$ hairs $(15.5 \%)$ and $4 />4$ hairs $(4.7 \%)$. The average hair per unit was 1.83 . The average area of safe donor zone was $119.9 \mathrm{~cm}^{2}$. The average total number of follicular units was 13,560 and total number of hairs was
26,573 in the safe donor area. The median thickness of hair was $0.056 \mathrm{~mm}$. Density of vellus hair and terminal hair was 56 and 133 per $\mathrm{cm}^{2}$ respectively (Table 1 ).

Follicular units, hair density, and grouping were highest in patients with grade III AGA and those in the age group 31 to 35 years (Tables 2 and 3).

\section{DISCUSSION}

Assessment of the donor zone is a prime important step in hair transplantation surgery. The safe donor zone is defined by lack of significant miniaturization. There are approximately 12,500 follicular units in the safe donor zone, out of which $50 \%$ of grafts can be safely moved from the donor zone. There can be shrinkage of donor zone by ascending hairline, characterized by miniaturization in the lower margin of the permanent zone at the back of the scalp. 


\begin{tabular}{ll}
\hline \multicolumn{2}{c}{ Table 1: Mean results of various parameters } \\
\hline$N=30$ & Mean \\
\hline Age & 29.2 years \\
Duration & 6.2 years \\
Donor area/cm ${ }^{2}$ & 119.9 \\
Hair follicular units $/ \mathrm{cm}^{2}$ & 112.5 \\
Hair density $/ \mathrm{cm}^{2}$ & 220.5 \\
1 hair & $42.3 \%$ \\
2 hairs & $37.5 \%$ \\
3 hairs & $15.5 \%$ \\
$>4$ hairs & $4.7 \%$ \\
Average hair/unit & 1.8 \\
Median thickness $(\mathrm{mm})$ & 0.056 \\
Density of vellus hair $/ \mathrm{cm}^{2}$ & 56.8 \\
Density of terminal hair $/ \mathrm{cm}^{2}$ & 133.4 \\
Total no of units & 13,560 \\
Total no of hairs & 26,573 \\
\hline
\end{tabular}

The selection criteria for hair transplantation include the grade of baldness, age of the patient, and rapidity of progression of the baldness. The AGA grades III to V are eligible for hair transplant surgery. Nowadays, there is an increased awareness among the youngsters; hence, the patients with lower grade of AGA are seeking hair transplantation. It is also true that some patients come very late in their advanced grade of baldness. If the donor area is good and the patients accept the results in permissible limits, hair transplantation can be also done in advanced grade of baldness. Studies show that there are 1 lakh hair or 50,000 follicular units on the scalp; among them 12,500 are in occipital region and 6,500 can be safely moved from the occipital safe zone to recipient site. By complete trichoscopic analysis of the donor area in the form of density, grouping, and terminal vs vellus hair, we can plan the exact number of grafts that can be safely moved from the donor to the recipient site. There is a significant racial variation in the hair density and follicular unit density among Caucasians, Asians, and
Africans. Africans have a lower hair density (average 160 hairs $/ \mathrm{cm}^{2}$ ) than Asians (average 170 hairs $/ \mathrm{cm}^{2}$ ) and Caucasians (average 200 hairs $/ \mathrm{cm}^{2}$ ). ${ }^{2}$ There are no welldocumented studies among Asians or Indians. In a study conducted by Bernstein and Rassman, ${ }^{2}$ the total number of follicular units was 70 to $95 / \mathrm{cm}^{2}$. Another study by Jimenez and Ruifernández $z^{3}$ concluded that the follicular unit density was between 65 and 85 units $/ \mathrm{cm}^{2}$ and the hair density was between 120 and 200 hairs $/ \mathrm{cm}^{2}$. Limmer ${ }^{4}$ found a range of 120 to 240 hairs $/ \mathrm{cm}^{2}$ and Haber ${ }^{5} 144$ to 176 hairs $/ \mathrm{cm}^{2}$. The majority of the hair emerges as 2-hair follicular units. The second most common unit is the 3-hair unit. The density and grouping in Asians are less compared with the Caucasians. In our study, we measured the safe donor zone and calculated the donor area, which varied among the patients and with size of the scalp. Our study shows average total number of follicular units as 13,560 and total number of hairs as 26,573 in the safe donor area, and it correlated with previous studies. Density and grouping are genetically determined. We also observed the density and grouping to be less on the sides compared with the center of safe donor zone. We observed age-related changes in donor zone like shrinkage of donor zone with decreased number of follicular grafts and increased single follicular units with increased aging; however, there was no change in hair thickness (Table 1). There was decease in hair follicular unit density, hair density, and median thickness of hair with advancing baldness (Table 2). The anagen to telogen ratio and terminal to vellus ratio varied with progressive rate of baldness and also the type of baldness (anterior pattern/ diffuse pattern). We observed some of the scalp changes like shrinkage of donor zone by ascending hairline and also diffuse thinning of the donor zone (diffuse unpatterned AGA), which requires further studies and evaluation. ${ }^{6}$ The dermoscopic evaluation proves valuable in the

Table 2: Variation of parameters according to the age of the patients

\begin{tabular}{|c|c|c|c|c|c|c|c|c|c|c|c|}
\hline $\begin{array}{l}\text { Age group } \\
\text { (years) }\end{array}$ & $\begin{array}{l}\text { Donor } \\
\text { area/cm } / \mathrm{cm}^{2}\end{array}$ & $\begin{array}{l}\text { Hair follicular } \\
\text { units } / \mathrm{cm}^{2}\end{array}$ & $\begin{array}{l}\text { Hair } \\
\text { density/cm } 2\end{array}$ & $\begin{array}{l}1 \text { hair } \\
\%\end{array}$ & $\begin{array}{l}2 \text { hairs } \\
\%\end{array}$ & $\begin{array}{l}3 \text { hairs } \\
\%\end{array}$ & $\begin{array}{l}\text { 4/>4 } \\
\text { hairs \% }\end{array}$ & $\begin{array}{l}\text { Average } \\
\text { hair/unit }\end{array}$ & $\begin{array}{l}\text { Median } \\
\text { thickness (mm) }\end{array}$ & $\begin{array}{l}\text { Total no } \\
\text { of units }\end{array}$ & $\begin{array}{l}\text { Total no } \\
\text { of hairs }\end{array}$ \\
\hline$<25$ & 130 & 110 & 216 & 42 & 38 & 15 & 5 & 1.82 & 0.054 & 14577 & 28348 \\
\hline 26 to 30 & 119 & 111 & 217 & 42 & 37 & 15 & 5 & 1.82 & 0.055 & 13297 & 26076 \\
\hline 31 to 35 & 115 & 116 & 234 & 40 & 37 & 16 & 5 & 1.87 & 0.058 & 13379 & 26994 \\
\hline$>35$ & 111 & 115 & 206 & 50 & 33 & 14 & 4 & 1.7 & 0.055 & 13106 & 23503 \\
\hline
\end{tabular}

Table 3: Variation of parameters according to the grade of AGA

\begin{tabular}{|c|c|c|c|c|c|c|c|c|c|c|c|}
\hline $\begin{array}{l}\text { Grades of } \\
A G A\end{array}$ & $\begin{array}{l}\text { Donor } \\
\text { area/cm }\end{array}$ & $\begin{array}{l}\text { Hair follicular } \\
\text { units } / \mathrm{cm}^{2}\end{array}$ & $\begin{array}{l}\text { Hair } \\
\text { density } / \mathrm{cm}^{2}\end{array}$ & $\begin{array}{l}1 \text { hair } \\
\%\end{array}$ & $\begin{array}{l}2 \text { hairs } \\
\%\end{array}$ & $\begin{array}{l}3 \text { hairs } \\
\%\end{array}$ & $\begin{array}{l}4 />4 \\
\text { hairs \% }\end{array}$ & $\begin{array}{l}\text { Average } \\
\text { hair/unit }\end{array}$ & $\begin{array}{l}\text { Median } \\
\text { thickness }(\mathrm{mm})\end{array}$ & $\begin{array}{l}\text { Total no } \\
\text { of units }\end{array}$ & $\begin{array}{l}\text { Total no } \\
\text { of hairs }\end{array}$ \\
\hline Grade III & 137 & 117 & 237 & 4 & 39 & 15 & 5 & 1.83 & 0.062 & 16107 & 32729 \\
\hline Grade IV & 131 & 110 & 215 & 41 & 38 & 15 & 5 & 1.84 & 0.056 & 14578 & 28514 \\
\hline Grade V & 111 & 116 & 227 & 43 & 36 & 16 & 5 & 1.84 & 0.054 & 12890 & 25384 \\
\hline Grade VI & 106 & 110 & 216 & 42 & 38 & 16 & 4 & 1.82 & 0.058 & 12008 & 23440 \\
\hline Grade VII & 111 & 108 & 203 & 43 & 37 & 12 & 6 & 1.76 & 0.052 & 12211 & 22737 \\
\hline
\end{tabular}


selection of patients for hair transplantation, documenting hair growth, and analyzing esthetic complications. ${ }^{7}$

\section{CONCLUSION}

The main advantages of pretransplant dermoscopic assessment are to calculate the total donor grafts, to plan the sessions depending on progression and grade of baldness, and lastly to help choose the technique of harvest. If follicular unit extraction (FUE) is done in the first session, there may be difficulty in harvesting grafts in the second session of FUE or follicular unit transplantation may not be possible as there are already reduced grafts in the area. If we know the number of grafts in the donor zone and area of good grouping, sessions of surgery can be planned depending on the grade and progression of baldness. In a young patient with grade III AGA, who requires only 1500 to 1800 grafts, planning can be done to harvest so many grafts without affecting the quality of the donor zone, by leaving safe zone for future harvest. This is the first kind of study that assesses the various above-discussed parameters of the donor zone with respect to age and advancing baldness.

We conclude that a thorough donor area assessment prior to hair transplantation is mandatory to assess the yield of grafts and overall treatment outcome. It is useful in planning the utilization of the grafts for present and future surgeries depending on patient's age and grade of baldness.

\section{REFERENCES}

1. Jain N, Doshi B, Khopkar U. Trichoscopy in alopecias: diagnosis simplified. Int J Trichology 2013 Oct-Dec;5(4):170-178.

2. Bernstein RM, Rassman WR. The logic of follicular unit transplantation. Dermatol Clin 1999 Apr;17(2):277-295.

3. Jimenez F, Ruifernández JM. Distribution of human hair in follicular units. A mathematical model for estimating the donor size in follicular unit transplantation. Dermatol Surg 1999 Apr;25(4):294-298.

4. Limmer BL. The density issue in hair transplantation. Dermatol Surg 1997 Sep;23(9):747-750.

5. Haber RS, Stough DB. Accurate estimation of graft requirements when using multibladed knives. In: Stough DB, Haber RS, eds. Hair replacement: surgical and medical. St. Louis: Mosby-Year Book, Inc. 1996:138-142.

6. De Lacharrière $O$, Deloche $C$, Misciali $C$, Piraccini BM, Vincenzi C, Bastien P, Tardy I, Bernard BA, Tosti A. Hair diameter diversity: a clinical sign reflecting the follicle miniaturization. Arch Dermatol 2001 May;137(5):641-646.

7. Madura C, Ravipati N, Chandrashekar BS. Clinical and trichoscopic correlation of scalp in patients who had undergone hair transplantation. Int J Dermascopy 2017 May-Aug;1(1):20-25. 